УДК 314.74

\title{
ВЛИЯНИЕ ВЫНУЖДЕННОЙ МИГРАЦИИ НА ПРИНИМАЮЩИЕ РЕГИОНЫ
}

\section{С.В. Мурашева}

Орловский государственный университет имени И.С. Тургенева, Орел, Россия, e-mail: murashova.svet@yandex.ru

Актуальность проблемы воздействия вынужденной миграции на принимающие регионы обусловлена все возрастающим количеством миграционных потоков, направленных из неблагополучных стран в более спокойные, богатые и процветающие государства. Миграция оказывает как положительное, так и отрицательное влияние на страны-реципиенты. Благодаря спросу на товары и услуги работников-иностранцев стимулируется дополнительная занятость, происходит быстрое развитие инфраструктуры, решается проблема дефицита рабочих ресурсов. Но в то же время приток приезжих ведет к снижению стоимости на рынке трудовых ресурсов, создает проблемы с внедрением технологий, сберегающих труд, понижает эффективность труда и его производительность, формирует дополнительную нагрузку на социальную инфраструктуру государства. При этом мигранты могут попытаться навязать собственную культуру местному населению, отрицая традиции принимающей страны, в связи с этим велика вероятность возникновения межэтнических конфликтов.

Целью представленной статьи явилось исследование специфики влияния вынужденной миграции на принимающие регионы. Важное место уделено вопросам адаптации и интеграции мигрантов в местах прибытия. Научная новизна предложенных в статье положений заключается в исследовании влияния вынужденной миграции на принимающие регионы. Практическая значимость заключается в возможности использования выводов статьи для разработки эффективной миграционной политики, успешной адаптации и интеграции вынужденных мигрантов в принимающее общество.

Ключевые слова: миграчия, вынужденные мигранты, межэтнические конфликты, адаптация и интеграция мигрантов, принимающее общество.

\section{INFLUENCE OF THE FORCED MIGRATION ON THE ACCEPTING REGIONS}

\author{
S.V. Murasheva \\ Oryol state university of I.S. Turgenev, Oryol, Russia, \\ e-mail: murashova.svet@yandex.ru
}

The relevance of a problem of impact of the forced migration on the accepting regions is caused by escalating quantity of the migration flows sent from the un- 
successful countries to quieter, rich and prospering states. Migration renders both positive, and negative influence on the countries recipients. Thanks to demand for goods and services of workers-foreigners additional employment is stimulated, there is a fast development of infrastructure, the problem of deficiency of working resources is solved. But, at the same time, inflow of visitors leads to depreciation in the market of human resources, creates problems with implementation of the technologies preserving work, lowers efficiency of work and its productivity, forms additional load of social infrastructure of the state. At the same time migrants can try to impose own culture to local population, denying traditions of the host country, in this regard the probability of emergence of the interethnic conflicts is high.

The purpose of the submitted article was the research of specifics of influence of the forced migration on the accepting regions. The important place is given to issues of adaptation and integration of migrants in places of arrival. The scientific novelty of the provisions offered in article consists in a research of influence of the forced migration on the accepting regions. The practical importance consists in a possibility of use of conclusions of article for development of effective migration policy, successful adaptation and integration of the forced migrants into the accepting society.

Keywords: migration, the forced migrants, the interethnic conflicts, adaptation and integration of migrants, the accepting society.

DOI 10.14258/ssi(2019)3-6279

\section{Введение}

В современной жизни общества перемещение населения, наряду с движением капитала, технологий, товаров, информации, представляет собой одну из важных составляющих процесса глобализации. Вынужденная миграция является реальностью нашего мира. На Земле, к сожалению, есть много стран, население которых в силу различных причин (например, из-за гражданской войны, острых конфликтов) стремится сменить место жительства в поисках лучшей жизни (а иногда и просто ради спасения от смерти), уехать из своего государства. При этом мигранты стараются переехать из опасной, бедной и неблагополучной страны в спокойное, богатое и процветающее государство. Так, весьма серьезной проблемой в последние годы для европейских стран стал наплыв беженцев с Ближнего Востока (из Ливии, Сирии, Йемена).

Как известно, Российская Федерация занимает третье место по числу мигрантов. По данным за 2018 г. число мигрантов в России составило 11,9 млн чел. Согласно Росстату большинство мигрирующих в Россию - граждане Узбекистана, Таджикистана, Казахстана и Украины. Миграционный прирост населения в России - важнейший фактор настоящего и будущего развития страны. По данным переписей населения, мигранты на $60 \%$ компенсировали естественную убыль населения. Такая ситуация в дальнейшем может привести к потере национальной и этнической идентичности титульного населения, собственной культуры. 
В советский период проблема вынужденной миграции в нашей стране фактически отсутствовала. Она стала объектом внимания ученых, государственных деятелей и журналистов лишь в 1990-х гг. в связи со стремлением к независимости многих бывших союзных республик и распадом Советского Союза. С жертвами насильственных перемещений Россия впервые столкнулась еще до распада СССР — это были люди, бежавшие от армянских погромов в 1988 г. в Сумгаите и в 1990 г. в Баку, турки-месхетинцы, спасавшиеся от погромов в Фергане в 1989 г. Потом был Нагорный Карабах, чечено-ингушский конфликт, гражданская война в Таджикистане, военный конфликт в Приднестровье, война в Абхазии, война в Чечне. Одновременно с этим активизировались начавшиеся еще задолго до распада СССР передвижения русскоязычных жителей из бывших советских республик в Россию, поскольку образование новых независимых государств привело к резкому ухудшению положения русских и представителей других этнических групп, считающих родным русский язык (Мурашева, 2013: 245).

В начале 2000-х гг. интерес к данной проблеме вновь был ограничен, что обусловлено повышенной активностью стран СНГ по выработке коллективных усилий в сфере управления миграцией. Россия была инициатором этих действий. В 2000-х гг. поток мигрантов в Российскую Федерацию состоял в основном из трудовых мигрантов.

В последние годы, по мере увеличения вынужденной миграции с востока Украины и других государств, проблема вынужденной миграции снова вышла на первый план. В отличие от предыдущих периодов исторического развития нашего государства, современная миграция плохо поддается авторитарным формам регулирования. Эту проблему в данных условиях необходимо решать новыми способами. Пока миграционная политика большинства государств отличается ситуативностью, фрагментарностью, недостаточен ее теоретический анализ и осмысление. В настоящее время миграция, включая ее вынужденные формы, предъявляет новые требования к деятельности органов государственной власти, к выбору тех механизмов, которые используются для ее урегулирования. При этом необходимо учитывать, что миграция опосредована самыми разными политическими и экономическими, социальными и культурными факторами (Зайончковская, 1994: 67).

\section{Позитивное и негативное влияние миграции}

Миграция оказывает как позитивное, так и негативное влияние на развитие общества, характер ее последствий противоречив. В частности, благодаря спросу работников-иностранцев на товары и услуги стимулируется дополнительная занятость, происходит быстрое развитие инфраструктуры, решается проблема дефицита рабочих ресурсов. За счет привлечения работающих мигрантов, не имеющих квалификации, для россиян становятся более доступными высокооплачиваемые виды труда. Очевидно, что мигранты менее притязательны относительно выбора видов деятельности, которые местных жителей не привлекают, за счет этого улучшается общий уровень и качество жизни людей, быстрее развивается строительство, сельское хозяйство и сфера услуг. К тому же невысокая стоимость «приезжей» рабочей силы увеличивает конкурентоспособность готовой продукции. 
Иностранные сотрудники более склонны к формированию сбережений, что способствует замедлению инфляции. Специалисты высокой квалификации, получившие образование за рубежом, приносят принимающим государствам прибыль, предоставляют интеллектуальные и трудовые ресурсы без предварительных вложений в их развитие либо создание. Мигранты обогащают культуру принимающего региона новыми элементами, при этом повышается толерантность местных жителей. Наконец, применительно к России частично решается демографическая проблема.

Вместе с тем нельзя забывать о существенных минусах миграции. Гастарбайтеры обычно большую часть заработанных денег отсылают на родину, что приводит к оттоку финансов из экономики страны, которая их принимает. Приток приезжих может способствовать демпингу на рынке трудовых ресурсов, что ведет к уменьшению заработной платы у местных работников, росту безработицы. Применение дешевой рабочей силы мигрантов создает проблемы с внедрением технологий, сберегающих труд, понижает эффективность труда и его производительность. Мигранты создают дополнительную нагрузку на социальную инфраструктуру государства (больницы, школы, детские сады, транспортную сеть и т.д.). Кроме того, если мигранты являются нелегалами, то они, используя местную инфраструктуру, не платят налоги стране пребывания (Акмалова, 2013: 178).

Массовая миграция может способствовать росту числа правонарушений в уголовной и экономической сфере. Мигранты могут попытаться навязать собственную культуру местному населению, отрицая традиции принимающей страны, в связи с этим велика вероятность возникновения межэтнических конфликтов (Манапова, 2013: 118).

В то же время отдающим регионам миграция может принести значительную пользу. Трудовая миграция увеличивает валютные доходы государств, экспортирующих рабочую силу. Например, применительно к Украине или Таджикистану речь идет о многих миллиардах долларов. Мигранты инвестируют свои деньги в отечественную экономику, привозя валюту на родину. Правда, за счет оттока работников с высокой квалификацией из государств-экспортеров понижается уровень научно-технологического потенциала страны. Это усугубляет экономические проблемы и закрепляет дифференциацию национальных экономик по уровню и качеству жизни людей (Витковская, 1994: 26).

\section{Влияние вынужденной миграции из Украины и Сирии на российское об- щество}

Декларируемая миграционная политика России в области вынужденной миграции в основном соответствует международным стандартам. При этом преобладают запретительные установки в части реального предоставления убежища мигрантам. Рассмотрим в этой связи влияние вынужденной миграции на российское общество на примере последствий событий, начавшихся на Украине в 2014 г. Они вызвали самое большое количество перемещений вынужденных мигрантов в Россию с момента распада СССР (Волох, 2015: 67).

В 2014 г. нормативно-правовая система нашего государства не была рассчитана на массовый приток вынужденных переселенцев за такой короткий промежуток 
времени. Однако произошедшие события пополнили историю России практическим опытом в сфере массового приема вынужденных мигрантов, с тем чтобы использовать его в интересах страны. Эти события стали основой для разработки межведомственных нормативно-правовых актов, регламентирующих прием, размещение и предоставление статуса вынужденным мигрантам. Размещение лиц, искавших убежище в субъектах РФ, регламентировалось на федеральном уровне, при этом отсутствовало сопротивление со стороны субъектов Федерации в приеме мигрантов.

Все вышеперечисленное способствовало некоторым успехам в адаптации и интеграции переселенцев. Дело в том, что Россия и Украина - страны безвизового въезда, а этнокультурные характеристики населения Востока Украины и России близки. Оказание помощи гражданам Украины было одобрено на высоком политическом уровне, разными общественными организациями, СМИ об этом писали с положительной точки зрения. Переселенцы получили организационную и материальную поддержку за счет благотворительной деятельности россиян. Издержки на социальную адаптацию и интеграцию со стороны государства были снижены благодаря наличию родственных связей в России у значительной части переселенцев. Наконец, большинство вынужденных мигрантов просили не убежище, а лишь разрешение на временное проживание после пребывания на территории РФ в течение 90 дней.

Российская Федерация, основываясь на гуманистических принципах, историко-географической общности с украинским народом, осуществляла политику открытости, несмотря на серьезную нагрузку, связанную с приемом вынужденных переселенцев. Тем более что в перспективе это могло сказаться положительно на социально-экономическом развитии нашей страны. Гражданам, прибывающим из Украины, была предоставлена возможность легализовать свое правовое положение в соответствии с Федеральным законом «О правовом положении иностранных граждан в Российской Федерации» либо обратиться с просьбой об убежище в соответствии с Федеральным законом «О беженцах» (Евтушенко, 2006: 67).

В целом действия государственной власти по поддержке граждан Украины, ищущих убежище, способствовали дальнейшему развитию страны. Уже на начальном этапе осуществлялась поддержка в СМИ приема вынужденных мигрантов, был организован сбор средств и гуманитарной помощи. Вскоре стало очевидным, что одним регионам вынужденные переселенцы могли бы принести пользу, другим же они станут только экономическим бременем. Поэтому Москва и Санкт-Петербург ввели «нулевую квоту», в рамках которой был прекращен прием заявлений о предоставлении временного убежища и статуса беженца.

Граждане Украины были вынуждены подавать заявления о предоставлении разрешения на временное проживание (РВП) в другие регионы. Для более эффективного использования ресурсов вынужденных мигрантов в интересах страны они направлялись в не самые благополучные с экономической точки зрения регионы. Действительно, в таких субъектах Федерации мигрантам дешевле создать необходимые жилищные условия. В результате значительная часть лиц, ищущих убежище, отказались ехать в предусмотренные субъекты, часть из них вернулась в экономиче- 
ски более развитые субъекты РФ. Вместе с тем часть переселенцев все-таки поехали в регионы, способствуя тем самым смягчению проблемы нехватки рабочей силы и квалифицированных кадров.

Часть вынужденных мигрантов не намеревались интегрироваться в российское общество, надеясь в ближайшее время возвратиться на родину. Поэтому в ходе приема вынужденных мигрантов основной упор делался на их размещение у родственников и получение разрешения лишь на временное проживание. Те же, кто обращался за статусом, в основном просили временного убежища. За статусом беженца обращались редко. По мнению ряда экспертов, это было связано с «негласной установкой предоставлять временное убежище, устно отговаривать в подаче документов на статус беженца, при этом отличие статусов, в том числе по объему предоставляемых гарантий, заявителям не разъяснялось» (Баранов, 2014). При этом успешно решались социальные задачи, связанные с приемом вынужденных мигрантов, активно действовал некоммерческий сектор, а также граждане России, предоставившие различные виды поддержки.

В конце 2016 г. в России насчитывалось около 2,6 млн украинских граждан. В пунктах временного размещения находились около 16,4 тыс. чел., в частном секторе были размещены 567 тыс. чел. По разрешению на временное проживание находились более 325 тыс. чел, с видом на жительство - более 111 тыс., на учете состояли более 311 тыс. граждан Украины, имеющих статус беженца или временное убежище. В период с 2014 г. по 1 сентября 2016 г. участниками государственной программы по добровольному переселению в Россию соотечественников стали более 114 тыс. лиц, прибывших с Украины. Таким образом, РФ путем предоставления различных видов международной защиты оказала помощь более чем одному миллиону граждан Украины (Баранов, 2014).

Более сложные случаи миграции - это приезд переселенцев из регионов, которые не имеют с нашей страной какой-либо культурной и национальной общности. Неблагополучным регионом с этой точки зрения остается Афганистан. В 2016 г. из Афганистана в Россию прибыли 5,7 тыс. чел., что почти на $15 \%$ больше, чем в 2015 г. Пока не принято политического решения, и лишь единицам из 100 тыс. афганских граждан был предоставлен статус беженца или временное убежище. В 2017 г. на территорию РФ въехали более 9,2 тыс. граждан Сирии, что почти на 3\% больше, чем в 2016 г.

В течение 2018 г. российская государственная миграционная служба почти не предоставляла убежище гражданам Сирии, а тем, кто получил его ранее, отказывались его продлевать. Это привело к тому, что невеликое число тех, кто был счастливым обладателем временного убежища в России, за 2018 г. сократилось почти на 30\%. В своих решениях чиновники, ссылаясь на данные МИД РФ, писали, что граждане Сирии в целом не имеют препятствий для возвращения. Чиновников не интересовало, что ситуация в стране была по-прежнему очень опасная. На сегодняшний день в России находятся около 7 тыс. граждан Сирии. Ясно, что интеграция переселенцев из данных регионов в российское общество крайне затруднена, а их прием требует значительных расходов. 


\section{Пути совершенствования государственной миграционной политики в сфере вынужденной миграции}

Государственная миграционная политика в сфере вынужденной миграции требует разработки нормативных документов, регламентирующих массовый прием лиц, ищущих убежище. Необходимо научное обоснование подобных правовых актов, предварительная отработка возможных действий в случае массового приема вынужденных мигрантов с участием органов государственной власти, международных, некоммерческих организаций, религиозных объединений. Необходимо предусмотреть и случаи приема вынужденных мигрантов при отсутствии их преследования в стране исхода. Естественно, что все эти меры необходимо принимать лишь в контексте соблюдения экономических, политических и социально-культурных интересов российского государства.

В целях совершенствования миграционной политики нужно четко закрепить понятие «вынужденная миграция», ее основания, а также правила регулирования. Представляется необходимым также определить права и социальные гарантии для лиц, ищущих убежище, а также для получивших статус вынужденного переселенца, разграничить полномочия в миграционной сфере между РФ и ее субъектами, совершенствовать профессиональную подготовку кадров, работающих с вынужденными мигрантами.

Вместе с тем следует принимать меры с целью эффективного использования потенциала мигрантов в экономической сфере. В частности в последние годы в России трудится немало русскоязычных граждан Украины, имеющих высокий уровень образования. Упрощение для них процедуры получения вида на жительство или российского гражданства может существенно помочь им в решении экономических, социальных и демографических проблем.

С одной стороны, государственный механизм предоставления убежища должен гарантировать социально-экономическую, правовую, культурную и психологическую поддержку беженцев и лиц, получивших временное убежище. С другой стороны, помощь мигрантам не должна вредить национальной безопасности и внутренней стабильности РФ и ее отдельных регионов, мешать экономическому и социальному развитию страны (Гриценко, 2009: 167).

Проблемы в сфере миграции могут привести к негативным последствиям, в частности неспособность государства обеспечить помощь вынужденным переселенцам снижает международный престиж страны, ведет к невыполнению международных обязательств, утрате доверия к нашей стране (Проблемы.., 2004: 178). Решение проблемы вынужденной миграции требует от государства выработки и реализации четкой государственной политики в этой сфере деятельности. С одной стороны, она должна носить гуманитарный характер, а с другой - служить обеспечению безопасности государства в самом широком смысле слова.

\section{Роль неправительственных организаций в адаптации и интеграции ми- грантов \\ Современная вынужденная миграция происходит в условиях наличия в социуме разнообразных структур гражданского общества. Она активизиру-}


ет деятельность различных неправительственных организаций, появившихся в том числе и под воздействием миграционных процессов. Подобного рода общественные структуры могут активно участвовать в решении проблем, связанных с миграцией. В соответствии с Концепцией государственной миграционной политики в РФ неправительственные организации выступают в качестве равноправного и важного субъекта адаптационных и интеграционных процессов (Готлиб, 2000: 45).

Одной из государственных задач в области содействия адаптации и интеграции вынужденных мигрантов является «совершенствование взаимодействия федеральных органов государственной власти, органов государственной власти субъектов Российской Федерации и органов местного самоуправления с общественными объединениями, содействующими адаптации и интеграции мигрантов». Общественные организации становятся одним из основных партнеров государства при адаптации мигрантов (Готлиб, 2000: 56).

В сфере социальной поддержки некоммерческие организации (НКО) занимаются экспертной и аналитической деятельностью в области миграционных процессов, оказывают юридическую поддержку и правовое консультирование различных категорий переселенцев. НКО противодействуют распространению ксенофобии и способствуют пропаганде принципов толерантности среди принимающего населения. Немаловажно и содействие со стороны этих организаций адаптации представителей миграционного сообщества, помощи нуждающимся, в том числе финансовой поддержке, предоставление питания, средств личной гигиены, помощи в возвращении в страну исхода.

Себестоимость оказываемой помощи у НКО и негосударственных гуманитарных организаций (НГО) часто значительно ниже, чем у государственных учреждений, они более гибко реагируют на миграционные проблемы. Ряд общественных организаций ставит своей целью правовое и социальное консультирование мигрантов, разработку и реализацию стратегии оказания помощи в проблемной ситуации конкретного человека: содействие в подготовке необходимых документов, переговоpax с работодателями в случае задержки или невыплаты заработной платы, других нарушений трудовых прав.

Другие общественные организации активно функционируют в информационном поле, разрабатывают и распространяют необходимые материалы для мигрантов на русском и национальном языках (Гордон, 1994: 56). Часть таких организаций участвует в разработке рекомендаций, направленных на совершенствование законодательства и правоприменительной практики в сфере регулирования миграционных процессов. На наш взгляд, активная деятельность НКО (в которых работают тысячи людей, помогающих мигрантам) способствует развитию структур гражданского общества и правового государства в стране.

Действительно, многие неправительственные организации (НПО) осуществляют свою деятельность, основываясь на волонтерской поддержке. Волонтерство же представляет собой школу воспитания гражданской активности населения, способствует развитию демократических традиций общества. 
Следует отметить, что в Российской Федерации, как в государстве с массовой многонациональной миграцией, существуют общественные объединения, основанные активистами национальных диаспор. Данные организации в своей деятельности следуют национально-культурному вектору, в рамках которого работа этнических объединений ориентирована на сохранение культурной, национальной и этнической идентичности и отражает интересы этнических, национальных и культурных объединений. Самыми авторитетными организациями подобного рода выступают национально-культурные автономии (НКА) (Мурашева, 2015).

К сфере деятельности национально-этнических объединений закон относит также содействие социальной и культурной адаптации и интеграции различных категорий мигрантов. На сегодняшний день в рамках поддержки вынужденных мигрантов на территории РФ функционируют такие неправительственные организации, как «Мемориал», «Гражданское содействие», «ПСП фонд» и т.д. Деятельность НКО и НКА способствует развитию демократических традиций, толерантности в стране. Упомянутые НПО играют роль образовательного и адаптационного субъекта, проводя работу с детьми беженцев или женщинами-беженками по вопросу их переобучения и повышения квалификации.

Деятельность негосударственных организаций может быть успешно внедрена в федеральные и региональные программы по адаптации и интеграции вынужденных мигрантов, что является широко применяемой практикой как в России, так и за рубежом, доказавшей свою гибкость и эффективность (Гончарова, 2014: 197).

В европейской части России действуют более 200 организаций, направлениями работы которых являются защита прав мигрантов, беженцев, вынужденных переселенцев, воспитание толерантного отношения к мигрантам, социальная адаптация и интеграция мигрантов в новую для них социокультурную среду (Зайончковская, 1999: 45).

Значительную роль в содействии адаптации вынужденных мигрантов играют российские негосударственные общественные организации. Среди них можно выделить Общероссийскую общественную организацию «Федерация мигрантов в России», «Балтийский союз», «Башкирское республиканское общество беженцев», «Пристань» (Белгородская область), Санкт-Петербургское отделение Общероссийской общественной организации «Российский Красный Крест» и др. Несомненна польза от социального партнерства государства и негосударственного сектора в области адаптации объектов вынужденной миграции. Помимо помощи мигрантам, подобное партнерство способствует социокультурному развитию общества в целом.

В России негосударственные организации (некоммерческие организации, фонды, общественные объединения) могут не только оказывать мигрантам социальные услуги, соответствующие национальному стандарту, но и участвовать в подготовке законодательных инициатив, создании коллективных поселений с компактным проживанием мигрантов из конкретных государств. Для обеспечения интеграции и адаптации мигрантов в новую социокультурную среду негосударственные организации могут использовать ресурсы науки, туризма, спорта, бизнеса, осуществлять правовую защиту переселенцев. 
В России существуют международные организации, помогающие мигрантам. В нашей стране есть представительства Международной организации по мигрантам, Международного общественного движения содействия мигрантам и их объединения «Форума переселенческих организаций».

В настоящее время решены некоторые проблемы интеграции вынужденных переселенцев в российское общество. Этот статус, в частности, дает возможность получать государственное всеобщее среднее образование. Для лиц, признанных беженцами, и лиц, получивших временное убежище, имеется доступ к системе государственного медицинского страхования. Тем не менее остается много нерешенных вопросов, связанных с их адаптацией на территории России.

Возможности адаптации и интеграции для данной категории ограничены изза невозможности получения регистрации по месту проживания. Несовершенство правовых норм, интеграционной политики или государственных интеграционных программ продолжает оставаться главным препятствием для стабильного пребывания вынужденных мигрантов на территории России.

Миграция не должна быть проблемой для социально-экономического развития страны. При определенных условиях она позволяет привлекать в регионы РФ высококвалифицированных специалистов (Абдель Джалиль, 2017: 106). Необходимо, чтобы государство, осознав всю значимость миграции для социально-экономического развития как страны в целом, так и благосостояния отдельных регионов, активизировало свои усилия по регулированию миграционных процессов. Возможный положительный эффект от миграции во многом может быть обусловлен общей тенденцией к усилению межстранового сотрудничества в различных областях и координации политики государств на фоне интеграционных процессов в мире (Абдыкеримова, 2016: 107).

Формирование структур гражданского общества является одним из важных условий преодоления проблем, связанных с миграционными процессами, реализации положительного потенциала межнациональных отношений. Важное преимущество деятельности гражданского общества в сфере преодоления миграционных проблем - лучшее понимание регионального и местного своеобразия, большая гибкость и инновационные подходы, возможность непосредственного взаимодействия с национальными объединениями.

Особенно важна работа с социально уязвимыми категориями населения (беженцами, вынужденными переселенцами, лицами, получившими временное убежище), а также представителями национальных объединений. Только совместная деятельность государственной власти всех уровней, негосударственных общественных организаций и самих мигрантов может решить проблемы мигрантов, вынужденных переселенцев.

\section{Выводы}

Таким образом, вынужденная миграция для современной России оказалась проблемой, которая не нашла еще полного научного осмысления и не стала предметом применения для своего решения системы эффективных государственных меро- 
приятий. Анализ современного состояния миграционных процессов в РФ показал необходимость дальнейшего совершенствования миграционной политики.

Правильная миграционная политика может проводиться при оптимальном сочетании ряда условий. Прежде всего, при определении ее целей и средств нужно ориентироваться на интересы общества и его потребности. Важно, чтобы мероприятия по регулированию миграции служили социально-экономическому развитию региона и страны в целом, а не сводились к благотворительности.

Вынужденная миграция не должна вредить интересам Российской Федерации, отдельным гражданам. Неконтролируемый приток в нашу страну вынужденных переселенцев может привести к серьезным проблемам в области безопасности, росту терроризма, ухудшению социально-экономического развития страны, нарушению исторически сложившейся культурной идентичности нашего государства. Важным в этой связи является согласование программ социально-экономического развития региона и страны в целом с разработанными исходя из внешнеполитических условий планами миграционной политики.

\section{БИБЛИОГРАФИЧЕСКИЙ СПИСОК}

Абдель Джалиль Н.А. Особенности миграции и миграционной политики в Брянской области. PolitBook, 2017, No. 3, 106-108.

Абдыкеримова А.А. Эволюция миграционных процессов на постсоветском пространстве и его особенности. Наука, техника и образование, 2016, No. 8, 107-110.

Акмалова А.А. Социальная работа с мигрантами и беженцами. М.: ИНФРА-М, 2013.

Баранов А.В. Краснодарский край в 2014 году: мониторинг межэтнических отношений. Гуманитарные и юридические исследования, 2014, No. 4.

Витковская Г.С. Вынужденные переселенцы из ближнего зарубежья: проблемы интеграции в российский социум. Миграционные процессы после распада СССР, 1994, No. 5, 26-29.

Волох В.А. Новая Россия: политика и управление миграционными процессами. Самара: Бахран-М, 2015.

Гончарова Н.П. Отражение миграционной тематики СМИ в условиях эскалации межэтнических конфликтов. Социология в современном мире: наука, образование, творчество, 2014, No. 6, 197-199.

Гордон Л.А. Социальная адаптация в современных условиях. Социологические исследования, 1994, No. 8, 56-59.

Готлиб А.С. Социально-экономическая адаптация россиян: опыт сочетания количественной и качественной методологии в одном отдельно взятом исследовании. Социология, Т. 12, 2000, 56-63.

Гриценко Г.Д. Мигранты в социокультурном пространстве региона: социологические очерки. М.: Альфа-М, 2009.

Евтушенко В.И. Правовой статус беженца в Российской Федерации. Белгород: 
БГТУ, 2006.

Зайончковская Ж.А. Миграция специалистов в России: причины, последствия, оценки. М., 1994.

Зайончковская Ж.А. Миграция в разном масштабе времени. М., 1999.

Манапова В.Э. Миграция как фактор конфликтогенности. Вестник Адыгейского государственного университета, Сер. 1: Регионоведение: философия, история, социология, юриспруденция, политология, культурология, 2013, №. 1, 118-120.

Мурашева С.В. Причины конфликтогенности миграции. В кн.: Интеграция теории и практики в решении социальных проблем: материалы V Междунар. заоч. науч.-практ. конф. Орел: ОГУ, 2013, 245-249.

Мурашева С.В. Этноконфликтология (теоретико-методологические аспекты). Орел: ОГУ, 2015.

Проблемы социально-культурной адаптации мигрантов из стран СНГ в приграничных зонах Российской Федерации: материалы научно-практической конференции. Ч. 1. Тюмень, 2004.

\section{REFERENCES}

Abdel` Dzhalil’, N.A. (2017). Osobennosti migracii i migracionnoj politiki v Bryanskoj oblasti [Peculiarities of migration and migration policy in the Bryansk region]. PolitBook, no 3, 106-108.

Abdykerimova, A.A. (2016). Evolyuciya migracionnyx processov na postsovetskom prostranstve i ego osobennosti [Evolution of migration processes in the post-Soviet space and its features]. Nauka, texnika i obrazovanie [Science, Technology and Education], no 8, 107-110.

Akmalova, A.A. (2013). Social naya rabota s migrantami i bezhenczami [Social work with migrants and refugees]. Moscow: INFRA-M.

Baranov, A.V. (2014). Krasnodarskij kraj v 2014 godu: monitoring mezhetnicheskix otnoshenij [Krasnodar Territory in 2014: monitoring inter-ethnic relations]. Gumanitarnye $i$ yuridicheskie issledovaniya [Humanitarian and Legal Studies], no 4.

Vitkovskaya, G.S. (1994). Vynuzhdennye pereselency iz blizhnego zarubezh ya: problemy integracii $\mathrm{v}$ rossijskij socium [Internally displaced persons from the near abroad: problems of integration into Russian society]. Migracionnye processy posle raspada SSSR [Migration processes after the collapse of the USSR], no 5, 26-29.

Volox, V.A. (2015). Novaya Rossiya: politika i upravlenie migracionnymi processami [New Russia: Migration Policy and Management]. Samara: Baxran-M.

Goncharova, N.P. (2014). Otrazhenie migracionnoj tematiki SMI v usloviyax eskalacii mezhetnicheskix konfliktov [Reflecting the migration theme of the media in the context of the escalation of inter-ethnic conflicts]. Sociologiya v sovremennom mire: nauka, obrazovanie, tvorchestvo [Sociology in the Modern World: Science, Education, Creativity], no 6, 197-199.

Gordon, L.A. (1994). Social`naya adaptaciya v sovremennyx usloviyax [Social adaptation in today's environment]. Sociologicheskie issledovaniya [Sociological Research], no 8, $56-59$. 
Gotlib, A.C. (2000). Social’no-ekonomicheskaya adaptaciya rossiyan: opyt sochetaniya kolichestvennoj i kachestvennoj metodologii v odnom otdel`no vzyatom issledovanii [Socio-economic adaptation of Russians: experience of combining quantitative and qualitative methodology in one single study]. Sociologiya [Sociology], vol. 12, 56-63.

Gricenko, G.D. (2009). Migranty v sociokul turnom prostranstve regiona: sociologicheskie ocherki [Migrants in the region's sociocultural space. Sociological essays]. Moscow: Al’fa-M.

Evtushenko, V.I. (2006). Pravovoj status bezhencza v Rossijskoj Federacii [Legal status of refugees in the Russian Federation]. Belgorod: BGTU.

Zajonchkovskaya, Zh.A. (1994). Migraciya specialistov v Rossii: prichiny, posledstviya, ocenki [Migration of specialists in Russia: causes, consequences, estimates]. Moscow.

Zajonchkovskaya, Zh.A. (1999). Migraciya v raznom masshtabe vremeni [Migration over time]. Moscow.

Manapova, V.E. (2013). Migraciya kak faktor konfliktogennosti [Migration as a factor of conflict]. Vestnik Adygejskogo gosudarstvennogo universiteta, Ser. 1: Regionovedenie: filosofiya, istoriya, sociologiya, yurisprudenciya, politologiya, kul'turologiya [Bulletin of Adyghe State University, Ser. 1: Regional Studies: Philosophy, History, Sociology, Law, Political Science, Cultural Studies], no 1, 118-120.

Murasheva, S.V. (2013). Prichiny konfliktogennosti migracii [Causes of migration conflict]. In: Integraciya teorii $i$ praktiki $v$ reshenii social nyx problem: materialy $\mathrm{V}$ mezhdunar. zaoch. nauch.-prakt. konf. [Integration of theory and practice in solution of social problems] (pp. 245-249). Orel: OGU.

Murasheva, S.V. (2015). Etnokonfliktologiya (teoretiko-metodologicheskie aspekty) [Ethnoconflicology (theoretical and methodological aspects)]. Orel: OGU.

Problemy social no-kul 'turnoj adaptacii migrantov iz stran SNG v prigranichnyh zonah Rossijskoj Federacii [Problems of socio-cultural adaptation of migrants from CIS countries in border zones of the Russian Federation]: materialy nauchno-prakticheskoj konferencii (2004). Ch. 1. Tyumen`. 